\title{
Experimental study and FEM analysis of forward hot dieless spinning
}

\author{
Mohammad Sedighi*, Iraj Jalili, and Mehdi Kasaeian-Naeini \\ School of Mechanical Engineering, Iran University of Science and Technology, Tehran, Iran
}

Received: 27 January 2018 / Accepted: 4 August 2018

\begin{abstract}
In this study, the forward hot dieless spinning method is employed in order to fabricate conical tubes using thick aluminum. The process is first examined numerically and then verified by an experimental work. In the numerical study, a 3-D dynamic explicit model is used to solve a common problem in the modeling of the spinning process, the tube is fixed and the roller rotates around the tube. The strain distribution in the tube at various forming passes is studied. The numerical results show that the circumferential strain distribution in different positions of the tube has a negative value whose value increases toward the free end of the tube. Besides, the results indicate that the hardness of the sample increases by about $18 \%$ due to the hot dieless spinning process and such a hardness augmentation is obvious along the thickness of the formed tube.
\end{abstract}

Keywords: Spinning / dieless / tube / strain

\section{Introduction}

The forward hot dieless spinning process is one of the subcategories of mandrel-free spin forming method. In this process, a roller is moved on a predefined path, the material is flown in the roller movement direction and the tube is formed after several passes. This process can have similar advantages with ISMF process, because of the local contact between tool and workpiece which results in lower forming force [1-3]. The benefits of this method including: the variety of product shapes, dieless forming, less necessary equipment, and relevant cost have made it widely popular in various industries needing high precision material processing, such as automotive, aerospace and aviation industries.

Many studies have been conducted on the spinning processes including conventional and shear spinning. Alberti et al. [4] used the ADINA commercial code for the first time to numerically simulate the spinning process. Kang et al. [5] studied different modes of deformation in the process of conventional spinning and reported a similar thickness distribution for the conventional and shear spinning forming processes. Jianguo and Makoto [6] worked on the spinning of aluminum tubes by using two rollers and assessed the effect of pitch and reduction of the tube diameter on the surface roughness, forming forces, and the strain distribution along the thickness of the spun parts. Murata et al. [7] placed magnesium tubes at different

\footnotetext{
* e-mail: sedighi@iust.ac.ir
}

temperatures under a spinning process and observed that the forming limit will be increased significantly at a temperature higher than the recrystallization temperature. Akkus and Kawahara [8] presented an analytical method to predict the distribution of aluminum shell thickness formed by the spinning process. Incorporating an analytical contact model, Lexian and Dariani $[9,10]$ performed a numerical analysis for a tube spinning process. Furthermore, employing a non-linear FE method, they investigated the effect of roller geometry (i.e., the release angle and the radius of the roller) on forming quality in the hot spinning process of shells. Zoghi et al. [11,12] numerically examined the material deformation and the strain distribution in the process of tube spinning of steel tubes at a high temperature by finite element simulations. Besides, they investigated how the feed and initial locations of the roller affect the strain and residual stress distributions in the spinning of steel tubes with the spherical end at high temperatures. Xu et al. [13] used a 3DFE model of the tube spinning to obtain the strain and stress distributions corresponding to a different number of the rollers. Zhao et al. [14] presented a 3D coupled thermomechanical FE model for the multi-pass hot power backward spinning process of aluminum tubes and observed the augmentation of equivalent strain from the inner surface to the outer surface of the tube. Wang et al. [15] and Xu et al. [16] applied different damage models to reveal the fracture evolution in the forward tube spinning. Kuss and Buchmayr [17] minimized the damage effects during ball spinning by using a 2D-FEM model and the DOE method. Many researchers have investigated the 
Table 1. Percentage of the used aluminum alloy 6061-O.

\begin{tabular}{lllllllll}
\hline Element & $\mathrm{Al}$ & $\mathrm{Mg}$ & $\mathrm{Si}$ & $\mathrm{Cu}$ & $\mathrm{Fe}$ & $\mathrm{Mn}$ & $\mathrm{Cr}$ & $\mathrm{Ti}$ \\
\hline wt.\% & base & 0.96 & 0.59 & 0.241 & 0.186 & 0.0184 & 0.069 & 0.0092 \\
\hline
\end{tabular}

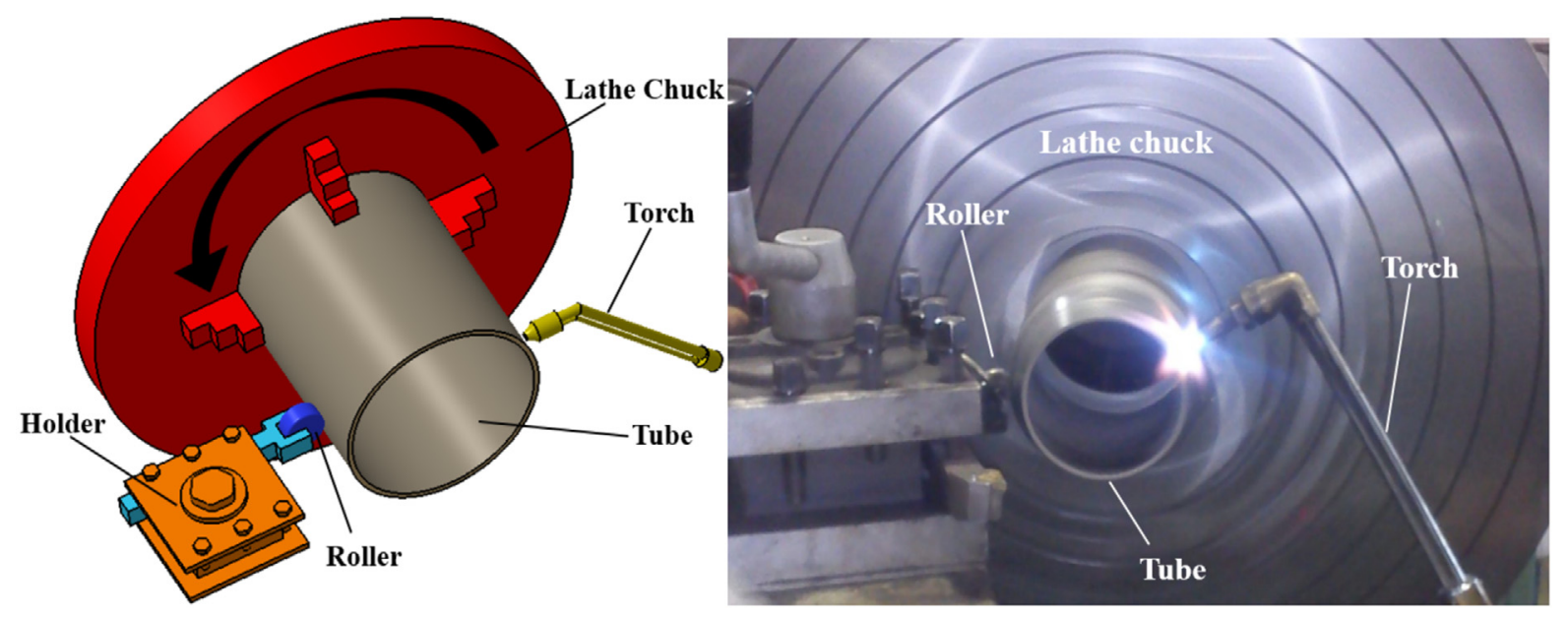

Fig. 1. The forward hot tube dieless spinning.

dieless spinning and analyzed different parameters of the process. Guo et al. [18] compared various roller path profiles and deformation allocations and presented the influence of them on product qualities. A new discretization method was proposed by Han et al. [19] to estimate the thickness distribution during dieless spinning. Jia et al. $[20,21]$ used dieless spinning to produce the square section cone and non-axisymmetric cone.

Nowadays, the need for high precision and costeffective processes is grown in the industries. Despite numerous investigation on the conventional spinning process, the hot dieless spinning process has been less considered. In this paper, an experimental work on the forward hot dieless spinning process for conical forming of an Al-6061 tube is presented and the feasibility of the proposed process is clarified. Hardness and optical images of the outer and inner surfaces of the formed tube are demonstrated. Next, the 3D dynamic-explicit FE-based analysis is performed for the numerical study of the process and it is validated by the experimental results. Finally, the resulting strain distributions and Von-Mises stress in five passes along the tube axis are rigorously examined.

\section{Materials and methods}

\subsection{Experimental work}

In this section, the materials, tool geometry, and parts used in the conducted experiments are first presented followed by describing the employed procedure for the experimental test. In order to perform a forward hot tube dieless spinning operation, the 6061-O aluminum tube was used (Tab. 1). Internal diameter and thickness of the tube were $140 \mathrm{~mm}$ and $5 \mathrm{~mm}$ respectively.
Table 2. Tools geometry, tube and experimental conditions.

\begin{tabular}{ll}
\hline Parameter & Value \\
\hline Workpiece & \\
Outer diameter (mm) & 150 \\
Wall thickness $(\mathrm{mm})$ & 5 \\
Initial length $(\mathrm{mm})$ & 208 \\
\hline Roller & \\
Diameter $(\mathrm{mm})$ & 30 \\
Width $(\mathrm{mm})$ & 10.7 \\
\hline Experimental condition & \\
Speed of rotation (rpm) & 100 \\
Feed rate (mm/rev) & 0.4 \\
Number of passes & 5 \\
\hline
\end{tabular}

Experiments are performed on a lathe with a big chuck for better tube clamping. Besides, a steel H13 roller was used in this work. For testing, the aluminum tube is fixed on the lathe and the temperature of the deformation zone is raised to $400^{\circ} \mathrm{C}$ by a torch. In order to create the defined shape on the tube, the roller is mounted on the lathe tool holder with the angle of $16^{\circ}$ and then it is moved toward the free end of the tube and the forming operation on the heated tube is performed. The apparatus utilized in the process is shown in Figure 1.

Table 2 indicates the tube dimensions and roller as well as the experimental conditions imposed during the tests. Furthermore, the paths of the roller, the amounts of forming in each pass and the final shape of the product after 
(a)

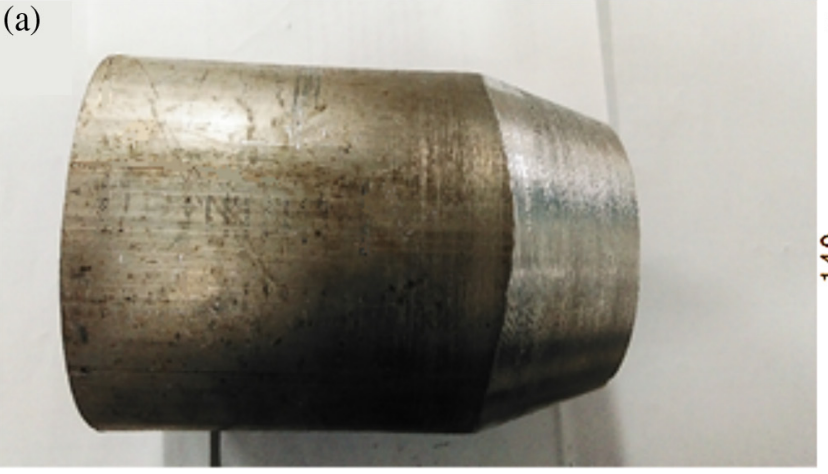

(b)

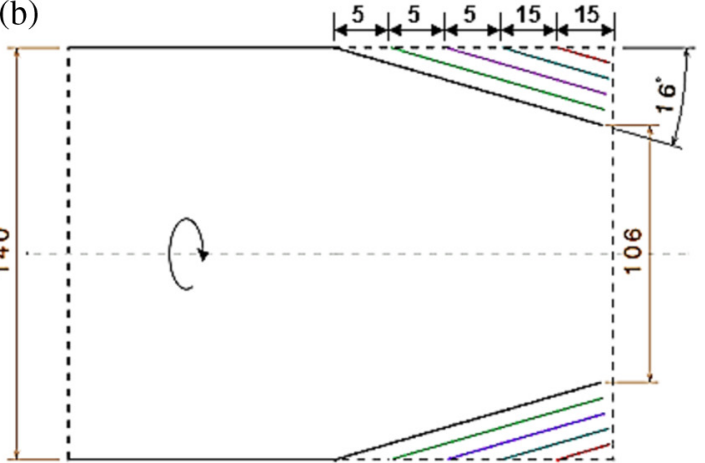

Fig. 2. (a) Schematic of 5 passes carried out in the experimental work; (b) the tube after forming.

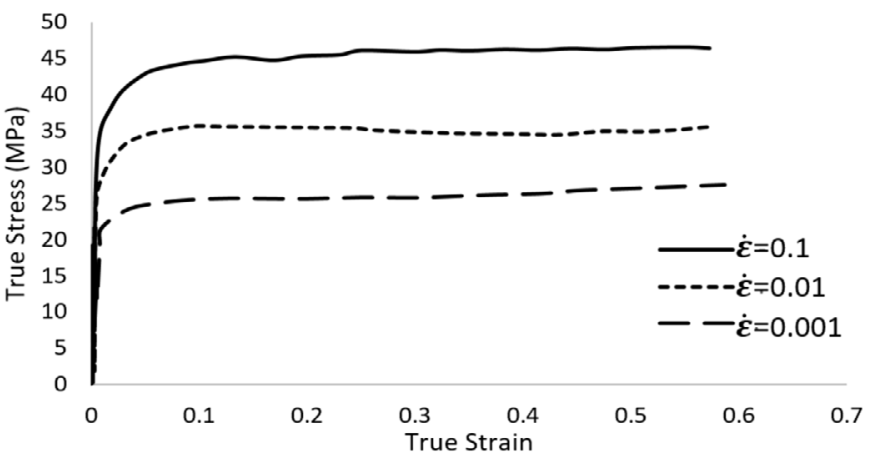

Fig. 3. Stress-Strain diagram of aluminum 6061 at $400{ }^{\circ} \mathrm{C}[23]$.

the process are schematically illustrated in Figure 2. The forming levels in each pass are determined by the equivalent strain computed in the $\mathrm{FE}$ models. These forming levels are considered as $15 \mathrm{~mm}$ for the first two passes and $5 \mathrm{~mm}$ for the next three passes.

To study the microstructure of the tube before and after the forming process, the specimens were prepared by sanding with progressively finer waterproof emery papers and polishing up to $1-\mu \mathrm{m}$ Alumina powders. Finally, the Barker's reagent was employed to etch the surfaces of samples. The hardness tests were fulfilled using a Vickers microhardness apparatus (Koopa KM3) with a load of $2 \mathrm{~N}$ and an applied time of $10 \mathrm{~s}$. For each hardness value, the hardness test was repeated five times and then the mean value was reported.

\subsection{Numerical procedure}

An explicit 3D finite element model in Abaqus 6.14 was used to simulate the process detailed above [22]. For this purpose, the tube and forming roller were modeled in accordance with the dimensions and geometry used in the experimental setup. The utilized material (Al6061-O) was considered to be dependent on temperature and strain rate. The Poisson ratio, elasticity module, and density of this material are $0.33,68.9 \mathrm{Gpa}$ and $2.7 \mathrm{~g} / \mathrm{cm}^{3}$ respectively and real stress - strain diagram of the material at $400{ }^{\circ} \mathrm{C}$ is shown in Figure 3 [23].

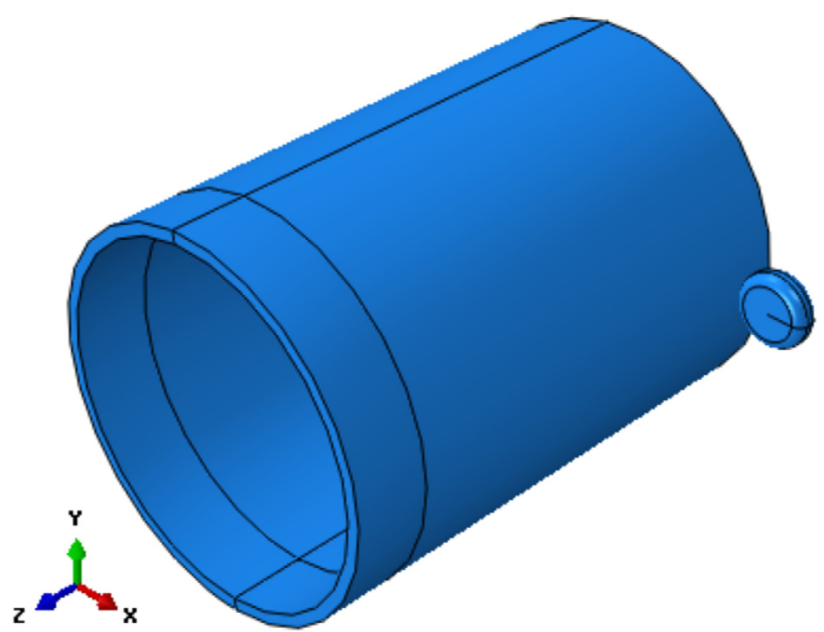

Fig. 4. The 3-D finite element model of the forward hot tube dieless spinning.

The 3D model of the process is shown in Figure 4. The tube was considered as deformable and C3D8R elements were utilized to capture the variation of the stress and strain along the thickness of the tube. However, it is noted that employing this type of elements in the simulations causes the run time to be increased compared with considering the shell elements. The roller was considered rigid and a penalty contact model between the roller and the tube was defined by applying the friction coefficient of 0.02 in the model [12].

To be able to capture a precise plastic deformation in the 3D simulations, a very large number of elements are needed, resulting in a higher computational cost. The mass scaling technique is utilized herein to reduce the computation time. Employing such a mass scaling causes the density of the material to be virtually increased, resulting in the enhanced time increments and consequently the shortened running time [12]. Here, it is also necessary to take into account the dynamic effects of using this technique. Therefore, contrary to the experimental work, the tube was fixed and the roller was moved in a tapered helical path along the tube axis. Incorporating 


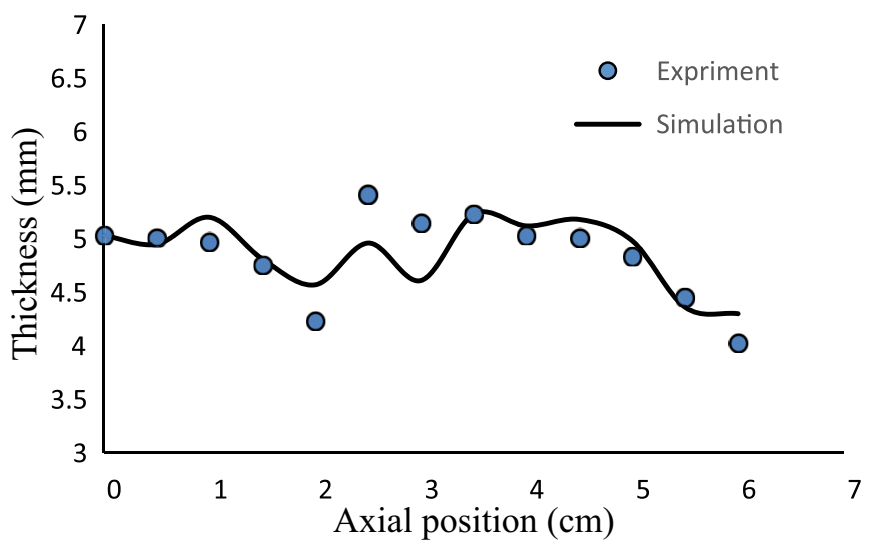

Fig. 5. Comparison of thickness distribution of experimental work and numerical simulation.

such a strategy in the simulations eliminates severe distortions of the elements due to the tube rotation. A mass scale factor equal to 50 was considered for this purpose.

As shown in Figure 2, the number of forming passes is 5 in the simulations same as the practical works in which the roller at the end of each pass moves to a far distance away from the free end of the tube and starts the next pass. Besides, a simultaneous solution method was utilized by taking advantage of two calculation cores to shorten the run time.

In order to verify the simulation results, the numerically obtained thickness variation of the formed part was compared with the corresponding amount observed in the experiment. Figure 5 illustrates the thickness distribution of the experimental work and its corresponding numerical simulation in which the horizontal axis shows the axial position of the tube. As can be seen, there is a good agreement between the numerical and experimental results. Nonetheless, the difference between the values could be due to the element distortions in the FEM simulations along with a possible error on the thickness measurement. As measured, the maximum deviation for the values is about $11 \%$.

As mentioned earlier, the mass scaling technique was used in numerical simulation to reduce the solution time. In order to verify the results obtained by employing this technique, the ratio of the kinetic energy to internal energy should be less than 0.1 during the analysis [24]. According to Figure 6 , the ratio first reaches about 0.65 , and decreases thereafter. However, in the rest of the process time, this ratio remains below 0.1 , which denotes that the dynamic effects in these simulations have been controlled properly $[25,26]$.

\section{Results and discussion}

In this section, the results obtained from Metallography and hardness test of the forming are presented, followed by showing the stress and strain distributions captured from the numerical simulations for the deformed area of the

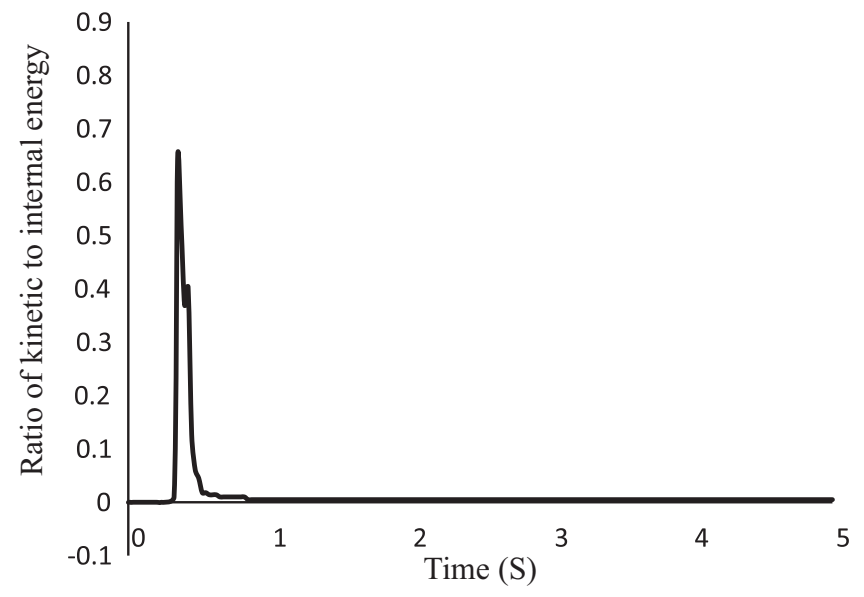

Fig. 6. Ratio of kinetic to internal energy versus time.

tubes. All discussions presented in this section are made based on the measurements at the end of each pass when the forming is completed.

Figure 7 shows the optical microscopy of the outside and inside surfaces before and after the forming process. As observed, the grains close to the outer formed surface were fined and elongated. It occurs mainly due to the frictional contact between the roller and the tube, resulting in an induced strain at the outer surface. However, in the grains far from the contact surface, less change is observed.

The hardness variation along the thickness direction is detailed in Figure 8. The sample hardness increases at the outer surface due to the fine graining and the occurring elongation. Furthermore, the hardness before the forming process is 61 Vickers that shows an increase of about $18 \%$.

The Von-Mises stress distributions are illustrated in Figures 9 and 10 for the 5 forming passes on the tube in the numerical simulation. As can be noted, increasing the number of passes has little effect on the maximum residual stress at the end of the passes. Strain and strain rate augmentation due to the number of passes and the increase in start point distance from the free end of the tube may be the causes of this phenomenon. Because, increasing the strain rate expands the flow stress and on the other hand increasing the strain reduces it. It was also observed that at the points close to the free end of the tube in each pass, the residual stress grows and reaches the maximum level.

According to the obtained results, the Von-Mises stresses highly increases toward the free end of the tube at the beginning and then after a relative reduction again increases. This trend, which was observed for all forming passes, is in line with results reported by Wang et al. [27] who conducted the finite element simulations of the conventional spinning process.

Figure 11 depicts the circumferential strain distribution for the five passes along the tube. As noticed, the strain is mostly gone toward the negative strain by moving to the free end of the tube. This trend is a predictable process because its diameter decreases with approaching the end of the tube. 

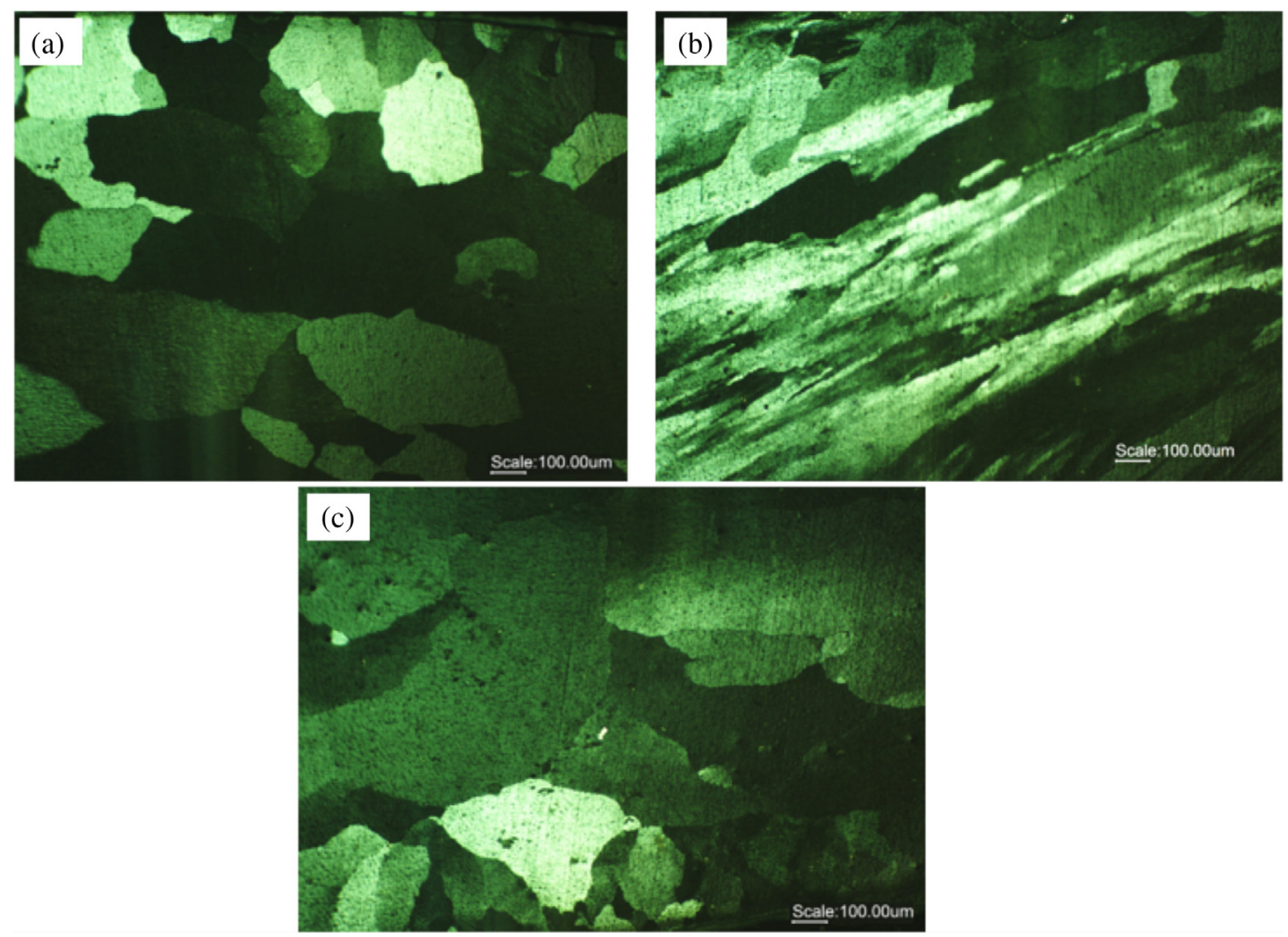

Fig. 7. (a) The outside surface of sample before the forming; (b) the outside surface of sample after the forming; (c) the inside surface of sample before the forming.

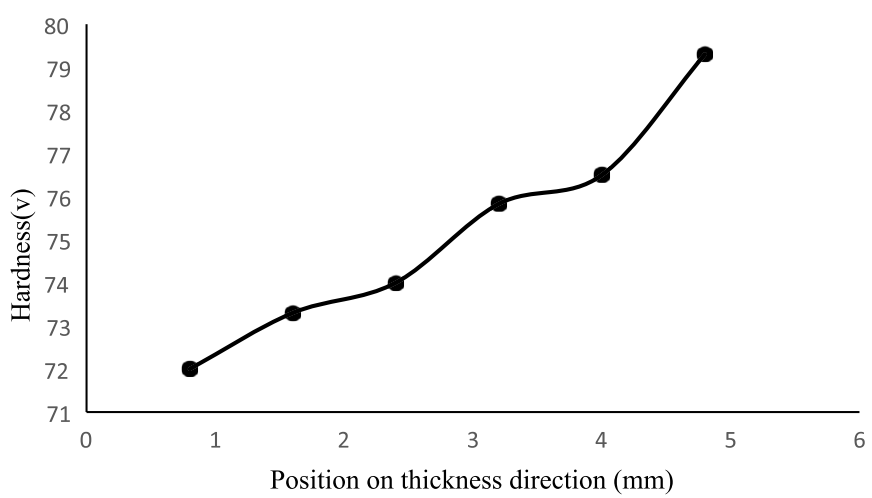

Fig. 8. Deformed sample hardness along the thickness of the tube.

Figure 12 illustrates the thickness strain distribution for the five passes of the formed conical tube. As can be seen, the thickness strain for all passes is negative at the beginning and its value increases toward the free end. Penetration of the roller into the work piece at the initial stages of the forming process could be the reason for this issue. However, afterward, the direction of the thickness strain changes and gains positive values in these five passes and close to the free end decreases intensely.
Figure 12 also shows a similar distribution between the last three passes while this resemblance was perceived between the two primary passes, as well. This similarity is because of the same penetration depth of the tool in these passes.

By observing the general trend of the thickness strain distributions for all passes, it is seen that the deformation mode can change based on the positions and various axial locations in the deformed tube.

The axial strain distribution of the tube after each pass is depicted in Figure 13. As can be noted, the axial strains are positive in the deformed region for all passes and have an ascending trend toward the free end of the tube. These behaviors were also reported in the flow forming on the studies performed by Haghshenas et al. [28] and Roy et al. [29]. Besides, the maximum axial strain at the final pass occurs with the similar trend in the thickness and circumferential strains.

In Figure 14, the equivalent strain distribution for the formed conical tube is displayed. As predicted, the equivalent strain has a growing trend while getting closer to the free end of the tube and the equivalent strain quantities have grown with increasing the number of passes. These results are consistent with the equivalent strain contour of the shell elements considered in the numerical simulations conducted and reported by Huang et al. [30]. 


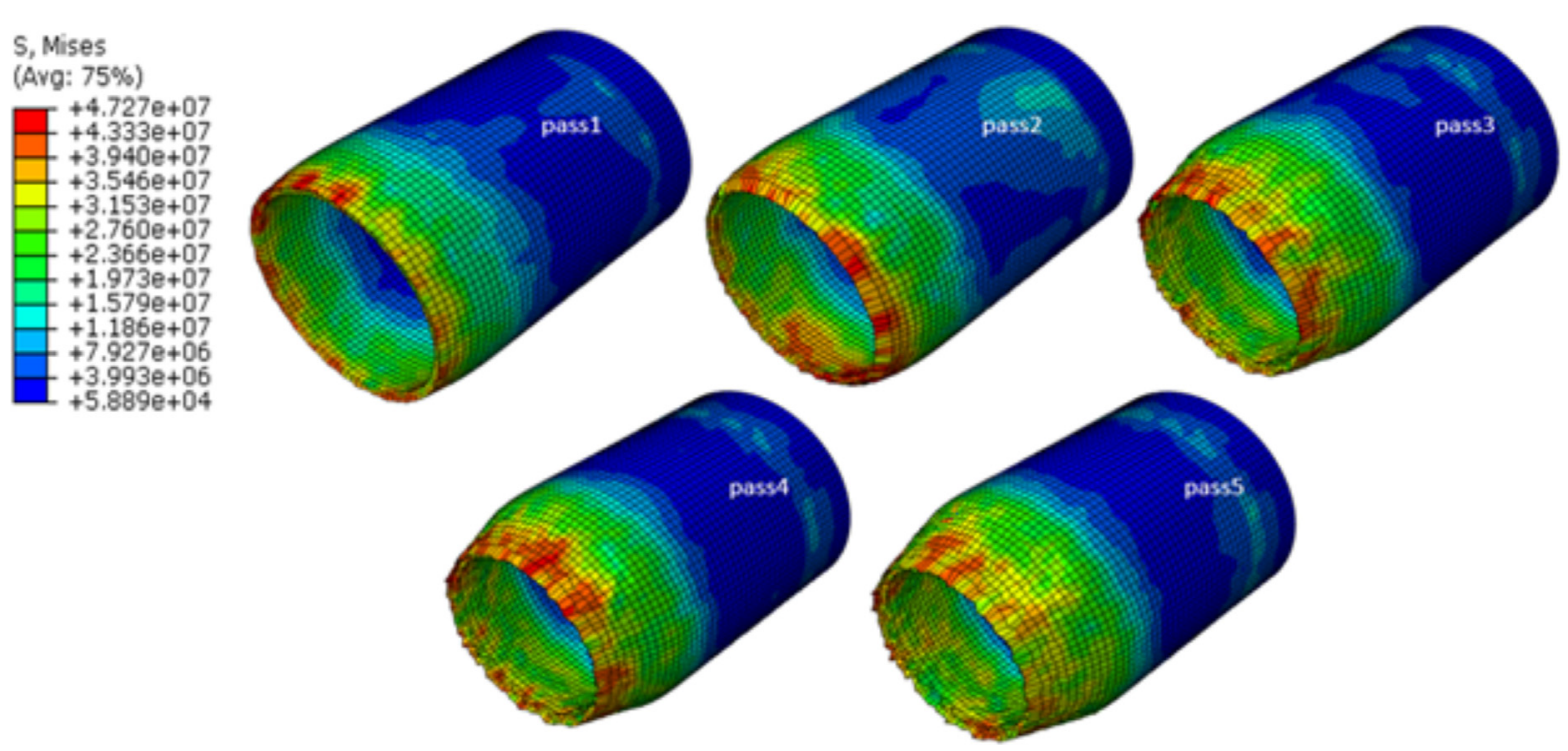

Fig. 9. The Von-Mises stress distributions at the end of each pass.
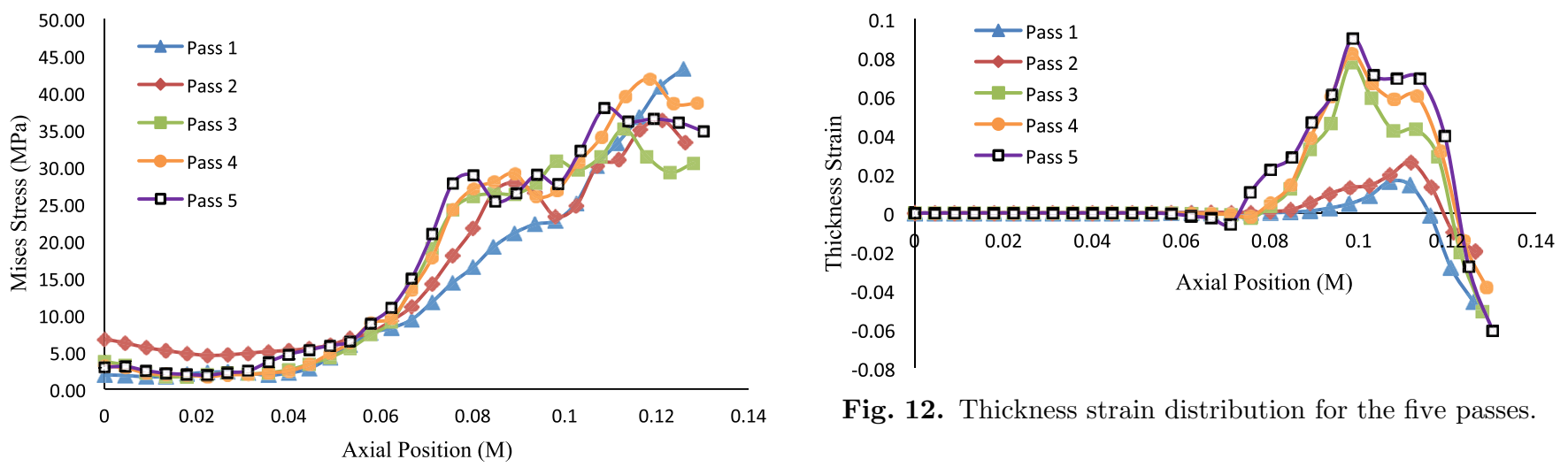

Fig. 12. Thickness strain distribution for the five passes.

Fig. 10. The Von-Mises stress diagram for five forming passes.
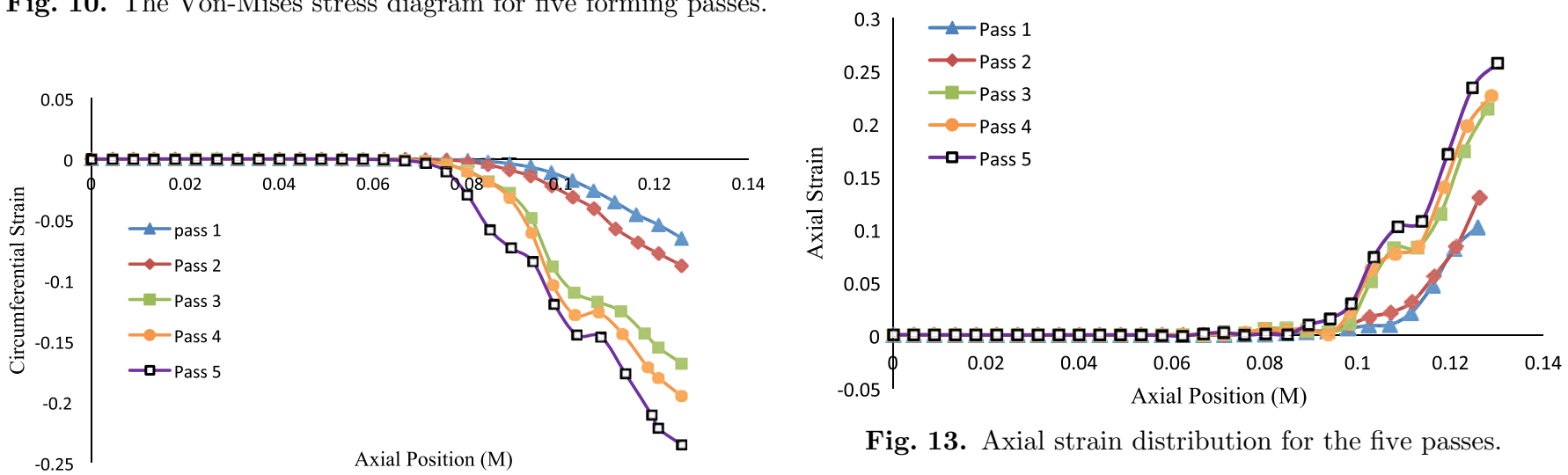

Fig. 13. Axial strain distribution for the five passes.

Fig. 11. Circumferential strain distribution for the five passes.

\section{Conclusion}

In this study, the forward hot dieless spinning process of the Al-6061 tube was performed experimentally and the corresponding numerical simulation was examined. From the results of this study, the following can be concluded:

- because of the benefits of this process - namely reduction of the forming forces, improvement of the product strength and diminishment of the final product cost - it can be widely used for producing pressure vessels and some parts in automotive industries;

- according to the optical microscopy images, grains were elongated and fined after the forming process. This effect was less observed for the inner surface. Furthermore, 


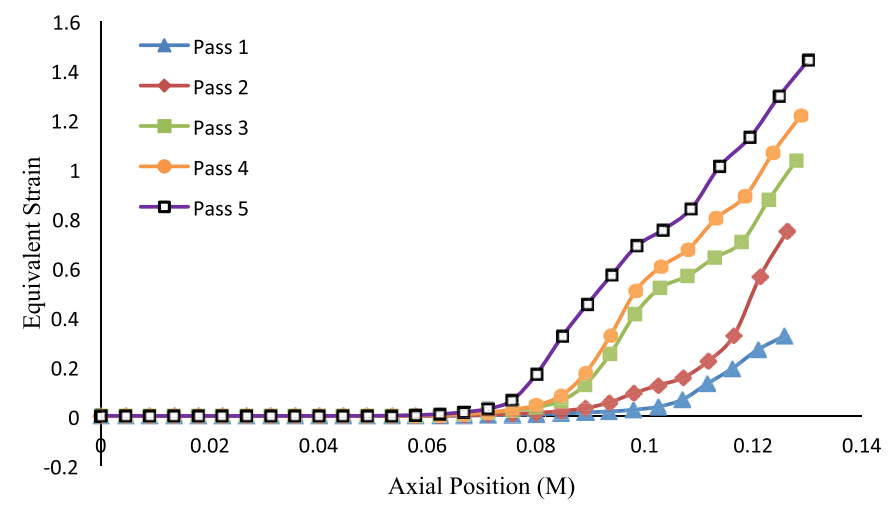

Fig. 14. The equivalent strain distribution for the five passes.

based on the results of the hardness test, the hardness was raised up to $10 \%$ for the outer surface along the thickness. Also, the hardness of the tube after the forming process was grown up from 61 to 72 and 79 Vickers for the inner and outer surface;

- augmentation the number of forming passes (consequential enhancement of the roller and the tube contact) did not have a considerable effect on the maximum residual stress in the formed tube. The stress had higher values in the free end of the tube. Besides, the equivalent strain had an ascending trend by increasing the number of the pass and getting close to the free end of the tube, which reached 1.5 for the pass 5 ;

- with approaching the free end of the tube, the circumferential strain on the pressure side (negative strains) increases and reaches its maximum at the end of the tube. Despite the circumferential strain, the axial strain for all passes is positive and its value increases along the tube. Moreover, with the augment of the pass number, both circumferential and axial strains raise;

- due to the penetration of the roller into the workpiece, the thickness strain for all passes was negative in the regions far from the free end and then it increased. After the strain direction changed into the positive values, at a portion of the tube, the distributions of the thickness strain represent negative strain values.

\section{References}

1 B. Saidi, A. Boulila, M. Ayadi, R. Nasri, Experimental force measurements in single point incremental sheet forming SPIF, Mech. Ind. 16 (2015) 410

2 L.B. Said, J. Mars, M. Wali, F. Dammak, Effects of the tool path strategies on incremental sheet metal forming process, Mech. Ind. 17 (2016) 411

3 A. Asgari, M. Sedighi, M. Riahi, Investigation of dimensional accuracy in incremental sheet metal hammering process: a parametric study, Mech. Ind. 16 (2015) 308

4 N. Alberti, L. Cannizzaro, E.L. Valvo, F. Micari, Analysis of metal spinning processes by the Adina code, Comput. Struct. 32 (1989) 517-525

5 D.-C. Kang, X.-C. Gao, X.-F. Meng, Z.-H. Wang, Study on the deformation mode of conventional spinning of plates, J. Mater. Process. Technol. 91 (1999) 226-230
6 Y. Jianguo, M. Makoto, Effects of indented feed of roller tool on parallel spinning of circular aluminum tube, J. Mater. Process. Technol. 128 (2002) 274-279

7 M. Murata, T. Kuboki, T. Murai, Compression spinning of circular magnesium tube using heated roller tool, J. Mater. Process. Technol. 162-163 (2005) 540-545

8 N. Akkus, M. Kawahara, An experimental and analytical study on dome forming of seamless $\mathrm{Al}$ tube by spinning process, J. Mater. Process. Technol. 173 (2006) $145-150$

9 H. Lexian, B. Dariani, An analytical contact model for finite element analysis of tube spinning process, Proc. Inst. Mech. Eng. Part B J. Eng. Manuf. 222 (2008) 1375-1385

10 H. Lexian, B. Dariani, Effect of roller nose radius and release angle on the forming quality of a hot-spinning process using a non-linear finite element shell analysis, Proc. Inst. Mech. Eng. Part B J. Eng. Manuf. 223 (2009) 713-722

11 H. Zoghi, A.F. Arezoodar, M. Sayeaftabi, Enhanced finite element analysis of material deformation and strain distribution in spinning of $42 \mathrm{CrMo}$ steel tubes at elevated temperature, Mater. Des. 47 (2013) 234-242

12 H. Zoghi, A. Fallahi Arezoodar, M. Sayeaftabi, Effect of feed and roller contact start point on strain and residual stress distribution in dome forming of steel tube by spinning at an elevated temperature, Proc. Inst. Mech. Eng. Part B J. Eng. Manuf. 226 (2012) 1880-1890

13 W. Xu, X. Zhao, H. Ma, D. Shan, H. Lin, Influence of roller distribution modes on spinning force during tube spinning, Int. J. Mech. Sci. 113 (2016) 10-25

14 G. Zhao, C. Lu, R. Zhang, Z. Guo, M. Zhang, Uneven plastic deformation behavior of high-strength cast aluminum alloy tube in multi-pass hot power backward spinning, Int. J. Adv. Manuf. Technol. 88 (2017) 907-921

15 X. Wang, M. Zhan, J. Guo, B. Zhao, Evaluating the applicability of GTN damage model in forward tube spinning of aluminum alloy, Metals 6 (2016) 136

16 W. Xu, H. Wu, H. Ma, D. Shan, Damage evolution and ductile fracture prediction during tube spinning of titanium alloy, Int. J. Mech. Sci. 135 (2018) 226-239

17 M. Kuss, B. Buchmayr, Damage minimised ball spinning process design, J. Mater. Process. Technol. 234 (2016) $10-17$

18 H. Guo, J. Wang, G.-d. Lu, Z.-h. Sang, Q.-h. Wang, A study of multi-pass scheduling methods for die-less spinning, J. Zhejiang Univ. Sci. A 18 (2017) 413-429

19 Z. Han, Z. Fan, Y. Xiao, Z. Jia, A research on thickness distribution of oblique cone in dieless shear spinning, Int. J. Adv. Manuf. Technol. 90 (2017) 2901-2912

20 Z. Jia, Q. Xu, Z. Han, W. Peng, Precision forming of the straight edge of square section by die-less spinning, J. Manuf. Sci. Eng. 138 (2016) 011006

21 Z. Jia, Z. Han, B. Liu, Z. Fan, Numerical simulation and experimental study on the non-axisymmetric die-less shear spinning, Int. J. Adv. Manuf. Technol. 92 (2017) 497-504

22 Abaqus analysis user's manual. ABAQUS Inc, USA, 2012

23 E. Badami, M.T. Salehi, S.H. Seyedein, Modeling high temperature flow behavior of an AL6061 Aluminium alloy, Iran. J. Mater. Sci. Eng. 11 (2014) 63-71

24 L. Wang, H. Long, Investigation of material deformation in multi-pass conventional metal spinning, Mater. Des. 32 (2011) 2891-2899 
25 G. Tian, Z.-q. Yu, Y.-x. Zhao, S. Evsyukov, X.-m. Lai, Effects of backward path parameters on formability in conventional spinning of aluminum hemispherical parts, Trans. Nonferrous Met. Soc. China 28 (2018) 328-339

26 J. Wang, T. Ge, G.-d. Lu, F. Li, A study of 3D finite element modeling method for stagger spinning of thin-walled tube, J. Zhejiang Univ. Sci. A 17 (2016) 646-666

27 L. Wang, H. Long, A study of effects of roller path profiles on tool forces and part wall thickness variation in conventional metal spinning, J. Mater. Process. Technol. 211 (2011) $2140-2151$

Cite this article as: M. Sedighi, I. Jalili, M. Kasaeian-Naeini, Experimental study and FEM analysis of forward hot dieless spinning, Mechanics \& Industry 19, 404 (2018)
28 M. Haghshenas, M. Jhaver, R. Klassen, J. Wood, Plastic strain distribution during splined-mandrel flow forming, Mater. Des. 32 (2011) 3629-3636

29 M. Roy, R. Klassen, J. Wood, Evolution of plastic strain during a flow forming process, J. Mater. Process. Technol. 209 (2009) 1018-1025

30 C.C. Huang, H.Y. Fan, C.H. Hung, J.C. Hung, C.R. Lin, Three Dimensional Finite Element Analysis on Neckspinning Process of Thick-Walled Tube at an Elevated Temperature, in Advanced Materials Research, Trans Tech Publ, 2012, pp. 269-277 